\title{
Research on Control System of 5-DOF Magnetic Suspension Flywheel Battery
}

\author{
Runxian Yang*, Tao Tao \\ Intelligent Manufacturing Department, Yangzhou Polytechnic Institute, Yangzhou 225002, China \\ "Email: yangrxypi@163.com
}

Received: March 28, 2021. Revised: August 7, 2021. Accepted: August 23, 2021. Published: August 25, 2021.

\begin{abstract}
With the continuous reduction of fossil fuels, pure gasoline vehicles and diesel vehicles will inevitably withdraw from the stage of history. In contrast, new energy vehicles have huge room for development. However, the battery life and charging time of new energy vehicles are two important factors restricting their development. Therefore, more efficient energy storage methods need to be studied. Compared with traditional batteries, the new flywheel battery has attracted more scholars' attention due to its advantages of high charge and discharge efficiency, large stored energy, and long life cycle. In order to improve the performance of the flywheel battery and reduce the loss, a five-degree-of-freedom magnetic levitation flywheel battery is proposed in the paper to replace the traditional bearing-supported flywheel battery. Usually, the research on flywheel battery only focuses on a single aspect, and there are few literature to analyze the entire flywheel battery control system. Hence, the structure and principle of the five-degree-of-freedom flywheel battery are first introduced in the paper to design the control system for the five-degree-of-freedom flywheel battery and build a simulation model with the help of the Matlab/Simulink software. Finally, an experimental platform for the five-degree-of-freedom flywheel battery is established to conduct the experimental study to verify the reliability of the control system. The experimental results show that the five-degree-of-freedom flywheel battery control system proposed in the paper has good performance and stability.
\end{abstract}

Keywords-five-degree-of-freedom flywheel battery, bearingless and brushless DC motor, magnetic bearing, control system

\section{INTRODUCTION}

I $\mathrm{n}$ order to achieve the long-term goals of the Paris Agreement, many European countries have successively introduced policies that ban the production and sale of gasoline and diesel vehicles to comprehensively promote pure electric vehicles, which brings new opportunities to the development of pure electric vehicles. China has also issued a number of policies and standards to encourage and regulate the development of the electric vehicle industry. As the core of the energy source of electric vehicles, battery life, charging and discharging speed, and charging piles that require special customization are all bottlenecks restricting the development of electric vehicles. The new flywheel battery [1-5] that utilizes the mutual conversion between electrical and mechanical energy improves the utilization of energy and the efficiency of conversion, which also has the advantages of long service life, clean and pollution-free, and has broad application prospects in the field of electric vehicle batteries. However, traditional mechanical bearings limit the speed of the flywheel battery-driven motor and increase friction and other losses. Therefore, a five-degree-of-freedom flywheel battery is proposed in the paper, including a three-degree-of-freedom hybrid magnetic bearing, a two-degree-of-freedom bearingless and brushless DC motor and a flywheel rotor, which can reduce loss and improve power quality. The structure and working principle of bearingless brushless DC motor are relatively novel. In order to obtain more ideal suspension performance, it is necessary to optimize the stator and rotor structure and winding form according to different working environment and requirements. In addition, the further optimization design of the structure of the bearingless brushless motor can minimize the coupling between torque and levitation force, reduce the influence of magnetic saturation and save materials. In addition, from the previous literature [6-15], the research on magnetic levitation flywheel batteries mostly focuses on the radial levitation force of magnetic bearings or bearingless motors, and there are few studies on the overall system of flywheel batteries. Hence, the structure and principle of the five-degree-of-freedom flywheel battery are first introduced in the paper to establish a control system for the five-degree-of-freedom flywheel battery with the help of the Matlab/Simulink for simulation research. Finally, an experimental platform for a five-degree-of-freedom flywheel battery is built using the prototype to conduct an experimental study on the overall performance of the flywheel battery. The results show that the five-degree-of-freedom flywheel battery proposed in the paper has good working performance. 


\section{FIVE-DEGREE-OF-FREEDOM FLYWHEEL BATTERY STRUCTURE}

The flywheel battery is a mechanical device that converts electrical energy into mechanical energy storage [16, 17]. The flywheel rotor is driven by the motor to rotate at high speed, and the energy is stored in the form of mechanical energy. When generating electricity, the motor is used as a generator, and the flywheel rotor drives the generator to generate electricity. Moreover, As a new type of motor with high speed, high efficiency, easy maintenance and good speed regulation performance, the bearingless and brushless DC motor is more suitable as the driving motor of the flywheel energy storage system. Therefore, in order to effectively reduce the loss of flywheel battery and improve power quality, as shown in Figure 1 , a five-degree-of-freedom magnetic levitation flywheel battery is proposed in the paper, including three-degree-of-freedom hybrid magnetic bearings, two-degree-of-freedom bearingless and brushless DC motor, flywheel rotor, shaft, auxiliary bearing, vacuum chamber and other parts.

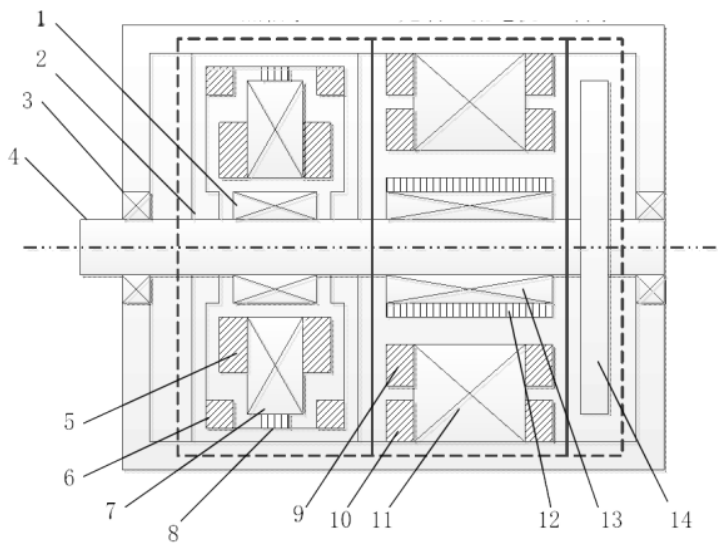

1. rotor of magnetic bearing 2. axial stator of magnetic bearing 3 . auxiliary bearing 4 . rotating shaft 5 . radial winding of magnetic bearing 6 . axial winding of magnetic bearing 7. radial stator of magnetic bearing 8. permanent magnet of magnetic bearing 9 . suspension force winding of motor 10 . torque winding of motor 11 . stator of motor 12. permanent magnet of motor 13. rotor of motor 14. rotor of flywheel

Fig. 1 The structure diagram of a five-degree-of-freedom flywheel battery

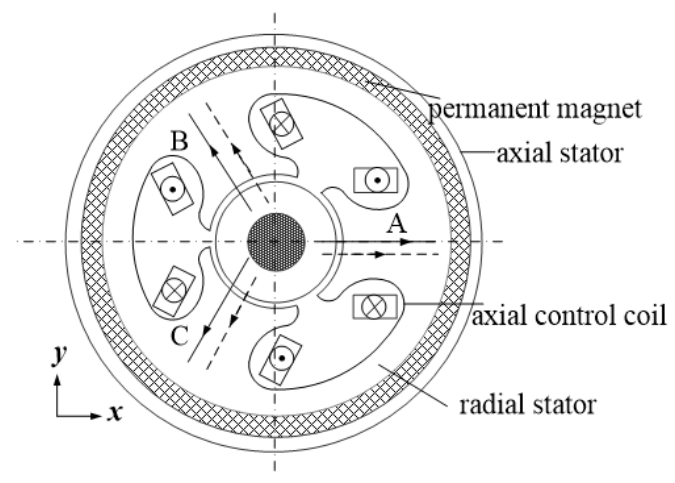

Fig. 2 Cross-sectional view of three-degree-of-freedom hybrid magnetic bearing
As shown in Figure 2, the three-degree-of-freedom hybrid magnetic bearing is composed of a radial stator, an axial stator, a rotor, an axial permanent magnet, a radial winding, and an axial winding. What is more, the rotor is arranged on the rotating shaft, and the radial part adopts a three-pole active magnetic bearing structure. The radial winding is wound on the radial stator to achieve radial suspension. Additionally, a magnetic isolation ring and an axial permanent magnet are added to the outside of the radial stator, and an axial stator and an axial winding are arranged on both sides of the permanent magnet to achieve axial suspension.

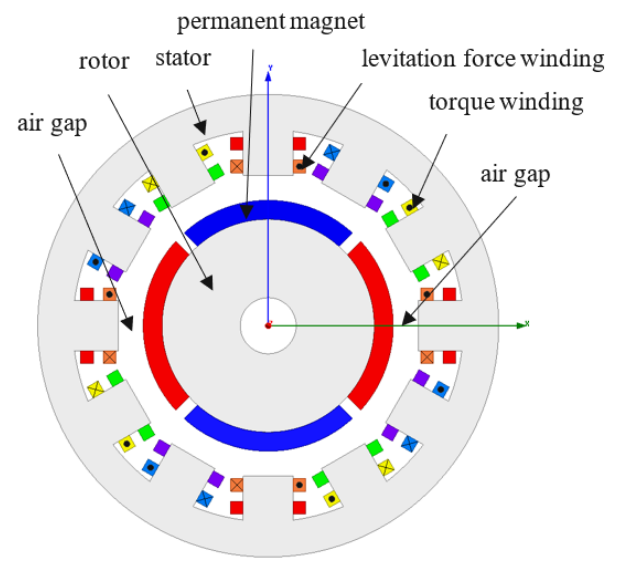

Fig. 3 Schematic diagram of suspension force principle

As shown in Figure 3, a two-degree-of-freedom bearingless and brushless DC motor is composed of a stator, a rotor, a torque winding, a suspension force winding, and a rotor permanent magnet. Moreover, the rotor is equipped with permanent magnets, which adopts a surface mount structure. A torque winding and a suspension force winding are respectively wound on the stator, wherein the pole pairs of the torque winding and the suspension force winding satisfy $p_{1}=p_{2} \pm 1$.

\section{OPERATING PRINCIPLE OF FIVE-DEGREE-OF-FrEEDOM FLYWHEEL BATTERY}

\section{A. Operating Principle of Bearingless and Rushless DC Motor}

When the bearingless and brushless DC motor is used as a motor, the real-time position of the rotor is detected and the conduction sequence of the stator winding is controlled to achieve the purpose of motor rotation. When the bearingless and brushless DC motor operates as a generator, the rotor is driven by the flywheel to rotate. The magnetic field cuts the conductor, and an induced electromotive force is formed in the conductor.

\section{B. The Principle of Magnetic Levitation}

The schematic diagram of the magnetic levitation of the bearingless and brushless DC motor is shown in Figure 3. By changing the size of the air gap magnetic density around the rotor, the rotor can be subjected to forces in different directions. Supposing that the angular position of the rotor shown in Figure 3 is $0^{\circ}$, when the angular position of the rotor is $0^{\circ}$, after the 
current shown in the figure is applied to the suspension winding in the direction of the current shown in the figure, the magnetic density at the air gap 1 increases, and the magnetic density at air gap 2 decreases, so that a levitation force along the positive direction of the x-axis can be generated. Similarly, when the suspension force winding in the vertical direction passes the current as shown in the figure, it will produce the suspension force in the positive direction of the y-axis, and the combination of the two is the resultant force on the rotor. When the angular position of the rotor changes, it is only necessary to change the conduction sequence of the suspension force winding to obtain the required suspension force.

\section{Operating Principle of Hybrid Magnetic Bearings}

In the hybrid magnetic bearing, the radial magnetic bearing can be regarded as a special bearingless motor with the pole pair number $p_{1}=0$ of the torque winding and the pole pair number $p_{2}=1$ of the suspension force winding (that is, the radial winding). The principle of force generation is similar to that of a bearingless motor, which satisfies the requirement of levitation force generation $p_{1}=p_{2} \pm 1$, and can only generate levitation force in the motor without generating torque. When the rotor is eccentric, the internal air gap magnetic field of the motor changes, and the magnetic density on the side with the smaller air gap increases, while the magnetic density on the side with the larger air gap decreases. At this time, the three-pole magnetic bearing is energized to generate a single-pole composite magnetic flux in the radial stator of the magnetic bearing, and the required levitation force can be obtained by changing the magnitude of the current. In addition, the levitation of the axial magnetic bearing is formed by the interaction between the magnetic field generated by the energization of the axial winding and the magnetic field generated by the axial permanent magnet.

\section{FIVE-DEGREE-OF-FrEEDOM FLYWHEEL BATTERY CONTROL SYSTEM}

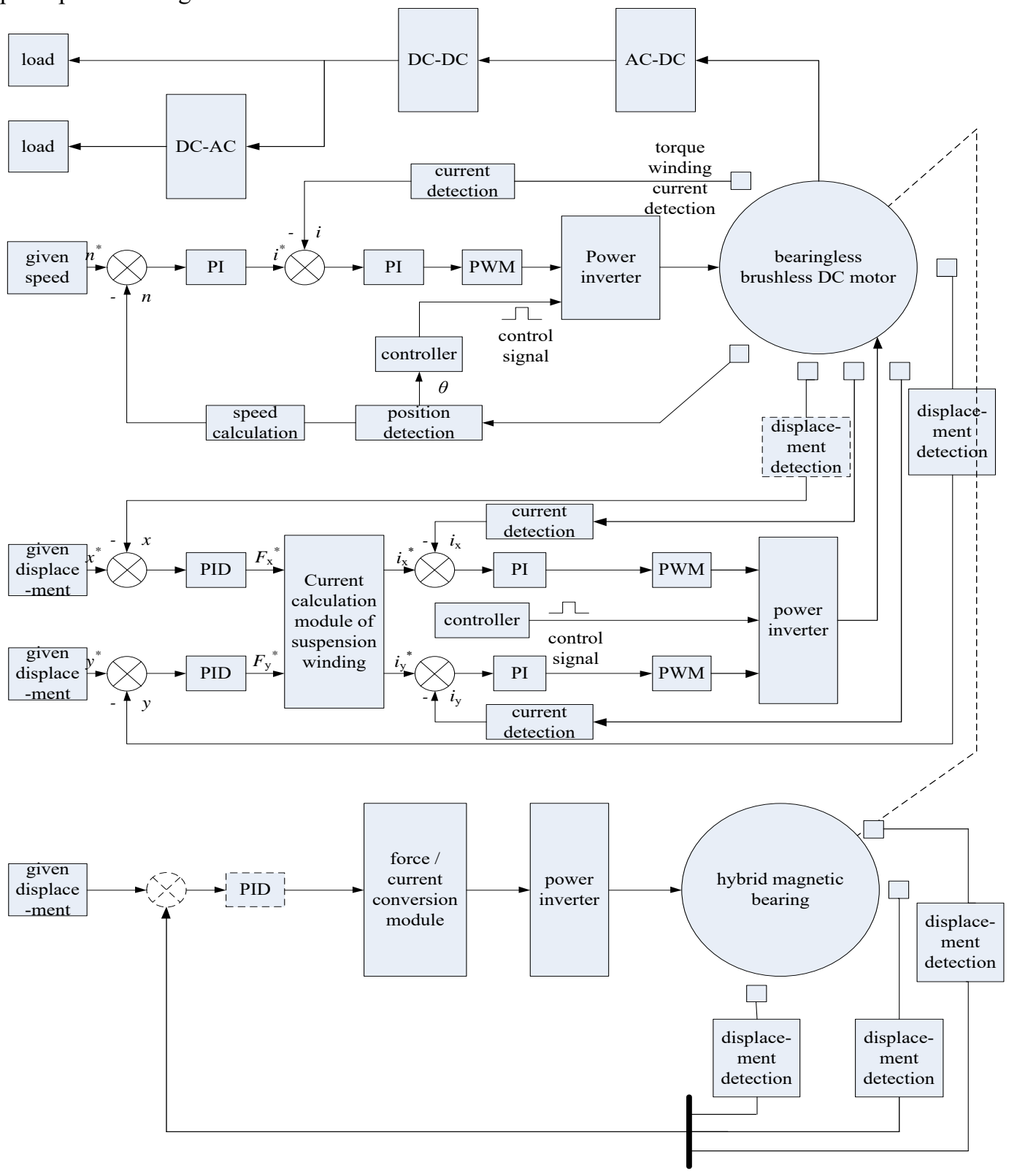


Fig. 4 Block diagram of a five-degree-of-freedom flywheel battery control system

Figure 4 is a block diagram of the control system of a five-degree-of-freedom flywheel battery, including the charging and discharging system of the bearingless and brushless DC motor, the levitation force control system, the radial levitation force system and the axial levitation force system of the hybrid magnetic bearing. In the flywheel energy storage system, the torque subsystem mainly controls the motor, standby and generator states of the bearingless brushless DC motor, corresponding to the charging, standby and discharging states of the flywheel energy storage system. The suspension force subsystem is powered by auxiliary power supply to ensure the rotor can be suspended stably in all States. The whole control system consists of voltage tracking inverter, PI / PID regulator, eddy current displacement sensor, Hall sensor, photoelectric encoder, controller and motor.

\section{A. Flywheel Battery Charging (Motor Mode) Control System}

The charging process of the flywheel battery is the process of converting electrical energy into mechanical energy and storing it. In other words, the rotation of the motor is controlled, so that the motor can drive the flywheel to a higher speed, and the inertia of the flywheel can be used to keep it rotating. Moreover, the speed of the flywheel rotor represents the remaining power of the flywheel energy storage system. As the speed of the flywheel rotor gets faster, the power it represents becomes higher and higher. When it reaches the rated speed and runs stably, it means that the power has been fully charged.

Therefore, the charging process of the flywheel battery can be reflected through the speed adjustment process of the bearingless and brushless DC motor. As shown in Figure 4, the bearingless and brushless DC motor is a permanent magnet motor that is controlled by detecting the angular position of the rotor, which adopts a speed and current double closed-loop speed regulation system and is controlled by a PI regulator. Meanwhile, the difference between the actual speed of the motor and the given speed is adjusted by PI to obtain the reference value of the current and form a closed loop of speed, and the difference between the current reference value and the actual value of the current is adjusted by PI to obtain a voltage signal and form a closed loop of current. Besides, the voltage signal is modulated by PWM, and then combined with the rotor position information, the trigger signal of the power inverter circuit is obtained to realize the speed regulation link of the bearingless and brushless DC motor.

\section{B. Control System of Flywheel Battery Discharge (Generator Mode)}

The discharge process of the flywheel battery is the process of converting the stored mechanical energy into electrical energy and releasing it. In other words, it is the process that the flywheel rotor relies on inertia to drive the generator to rotate, thereby generating electrical energy. The remaining power of the flywheel battery can also be reflected by detecting the size of the speed. What is more, the flywheel battery drive motor outputs three-phase symmetrical alternating current, while the induced electromotive force and voltage frequency of the flywheel battery drive motor are related to the speed of the flywheel. The faster the speed is, the greater the induced electromotive force will be, and the higher the voltage frequency will be, so the output of the flywheel battery Voltage is a changing curve. Therefore, the output of the flywheel battery needs to be rectified and filtered to obtain a stable direct current. Among them, the rectifier and filter circuit is composed of a bridge rectifier circuit. With the consumption of electrical energy, the mechanical energy continues to decrease, and the speed of the flywheel also decreases, which causes the situation that the output voltage of the flywheel battery decreases. Under this circumstances, a booster voltage regulator circuit will be added to ensure voltage stability. If $\mathrm{AC}$ power is needed, it can be converted into usable AC power through an inverter. When the electric vehicle drive motor adopts permanent magnet synchronous motor SVPWM to regulate speed, the direct current can be used directly for power supply.

\section{Control System of Flywheel Battery Magnetic Levitation}

The magnetic levitation control system of the flywheel battery includes a radial 2-DOF levitation force generated by a bearingless brushless DC motor, a radial 2-DOF levitation force generated by a magnetic bearing and an axial 1-DOF levitation force. In addition, the displacement current with double closed loop control system is adopted.

The control process of the magnetic levitation control system of the bearingless brushless DC motor is mainly as follows. The displacement of the rotor is first detected by the displacement sensor. Then, after the difference is made with the displacement reference value, the reference value of the suspension force will be obtained after the PID controller is adjusted. Finally, a closed loop of displacement is formed. Moreover, the reference value of the current is calculated through the relationship between the levitation force and the levitation force winding current. After the difference is made with the actual current, the voltage signal will be obtained after PI adjustment, and a current closed loop is formed at last. What is more, after the voltage signal is modulated by PWM, the trigger signal of the voltage source inverter will be obtained. However, the magnetic levitation control system of the magnetic bearing is slightly different. The rotor offset error is adjusted by the PID controller to obtain the levitation force. After the force/current conversion, it is output to the CRPWM current tracking inverter to directly obtain the input current of the magnetic bearing.

\section{Simulation EXPERIMENT}

According to the control system mentioned above, a simulation model is built in Matlab/Simulink software to carry out simulation experiment research. The research results are as follows.

\section{A. Speed response curve}

Figure 5 is the speed response curve of the bearingless and brushless DC motor, and the given speed is set to 3000rpm. 
From the figure, it can be seen that the speed reaches the given speed in about $0.075 \mathrm{~s}$ without overshoot, and the subsequent speed runs smoothly, showing that the control system has a good control effect.

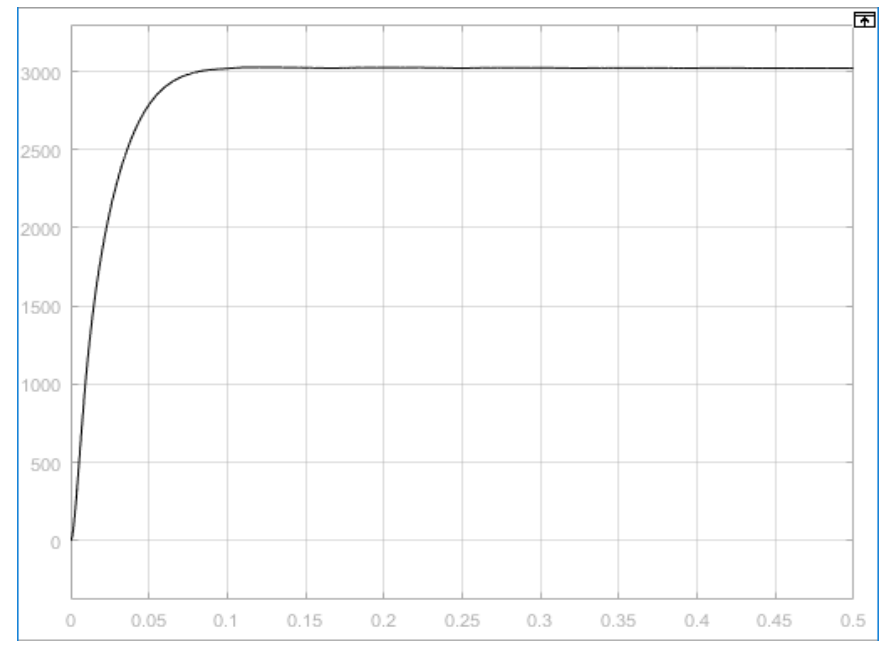

Fig. 5 Speed simulation curve

\section{B. Displacement response curve}

Figure 6 shows the $\mathrm{x}$-axis and $\mathrm{y}$-axis displacement response curves of the bearingless and brushless DC motor. It can be seen from the figure that the displacement of the $\mathrm{x}$-axis and $\mathrm{y}$-axis reaches 0 at $0.06 \mathrm{~s}$ and tends to be stable. The displacement overshoot is about $0.1 \mathrm{~mm}$, and the overshoot is less than the air gap length of $1 \mathrm{~mm}$, which indicates that the rotor has been stably suspended in the center, and the control system has a good control effect.

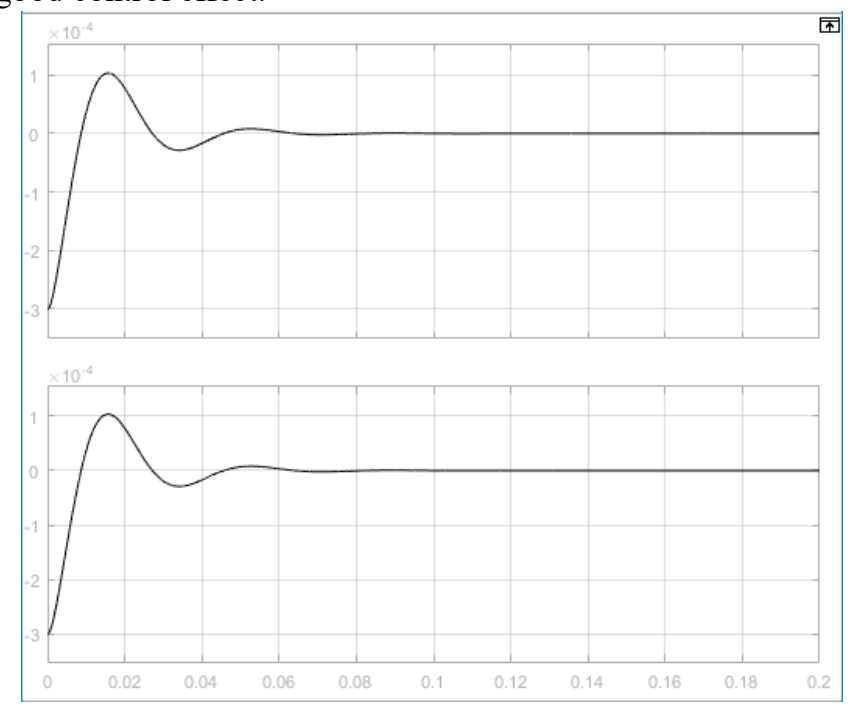

Fig. 6 Displacement simulation curve

\section{FlywheEl BATtery CONTROL System Test}

The flywheel battery experiment platform uses the TMS320F2812 DSP development board as the control core, and other functional circuits include interface circuit, power inverter circuit (IPM), displacement detection circuit (eddy current sensor), speed detection circuit (photoelectric encoder disk), current detection circuit ( Current transformer), voltage detection circuit (voltage transformer) and power supply equipment such as stabilized power supply and voltage regulator.

Experimental process: the control program is first written and compiled on the PC to ensure the correctness of the program, and then the compiled program is written into the DSP development board through the emulator. Moreover, the program is run to output the PWM wave. Finally, the motor is driven through the power amplifier module .

Comparing the charging experiment ( motor operation mode), discharge experiment (generator operation mode) and levitation performance experiment ( bearingless and brushless DC motor levitation and magnetic bearing levitation) on the flywheel battery experiment platform, the following experimental results are obtained.

\section{A. Charging Experiment (Motor Operation Mode)}

The charging experiment mainly tests the speed of the motor. Since in the flywheel battery, when the parameters of the flywheel rotor are fixed, the motor speed represents the speed of the flywheel, which is the power of the flywheel battery.

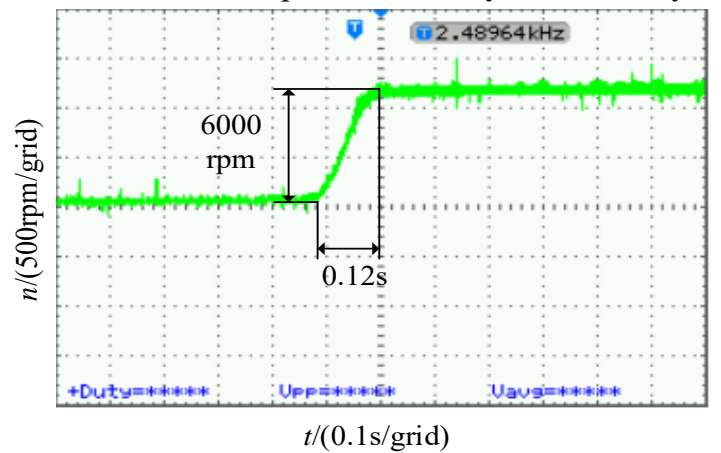

Fig. 7 Speed rising curve

Figure 7 is the speed response curve of the bearingless and brushless DC motor. The given speed is set to 6000rpm, and the speed rise time is $0.12 \mathrm{~s}$. The speed overshoot is small, and the subsequent speed runs relatively smoothly.

\section{B. Power Generation Experiment (Motor Operation Mode)}

Since the experimental platform is not equipped with a flywheel, the prime mover is used instead of the flywheel to simulate the power generation experiment. What is more, the prime mover speed is set to $3000 \mathrm{rpm}$, and the voltage values output by the rectifier filter module and the inverter module are measured respectively. In addition, Figure 8 is the voltage value output by the rectifier filter module, and the voltage is $180 \mathrm{~V}$, including the output voltage waveform after rectification and the output voltage waveform after filtering. It can be seen from the figure that the output DC voltage is relatively stable. 


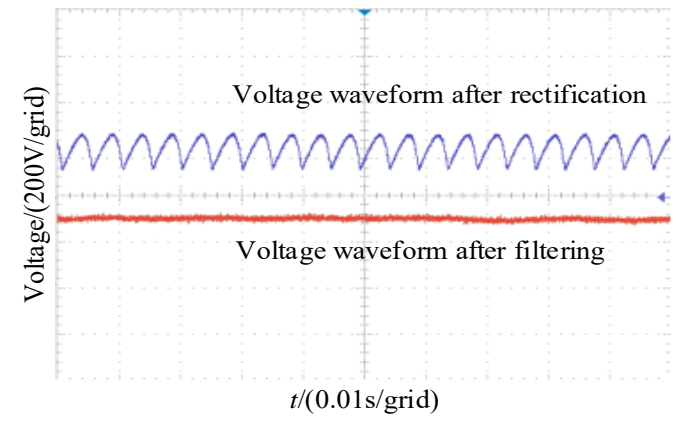

Fig. 8 Rectification and filtering waveform

Figure 9 is the AC voltage waveform after the DC power enters the inverter output. The figure shows a two-phase voltage waveform, and it can be seen from the figure that the output AC voltage waveform is $50 \mathrm{~Hz}$, which has good sinusoidality.

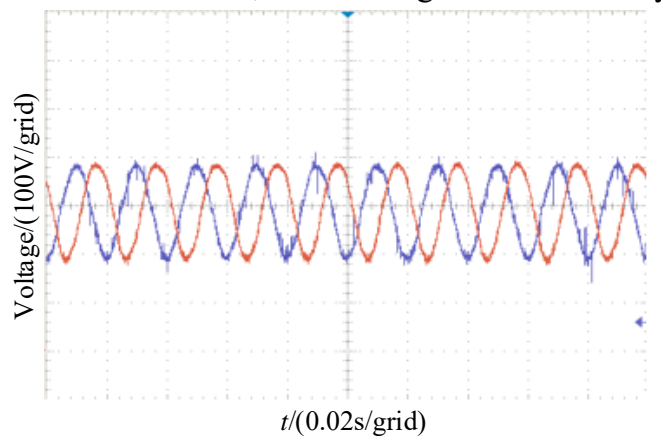

Fig. 9 Inverter output waveform

\section{Magnetic Levitation Experiment}

The levitation experiment includes the levitation performance test of the bearingless and brushless DC motor itself and the performance test of the magnetic bearing.

Figure 10 (a) and Figure 10 (b) are the radial displacement response curve and rotor trajectory diagram of the bearingless and brushless DC motor. It can be seen from the figure that the displacement in the $\mathrm{x}$-axis direction, only $0.1 \mathrm{~mm}$, is very small, which is much smaller than the air gap width of $1 \mathrm{~mm}$, while the displacement of the y-axis, $0.3 \mathrm{~mm}$, fluctuates slightly due to the influence of gravity, which is also small compared to the air gap. Therefore, the rotor trajectory can be seen approximately as an ellipse.

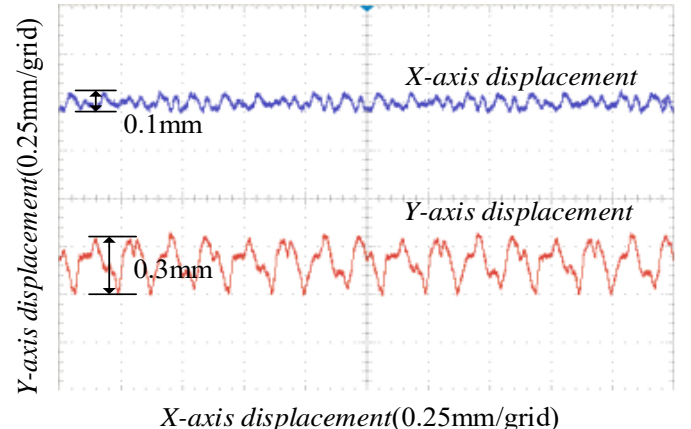

(a) Displacement in $\mathrm{x}$ and $\mathrm{y}$ directions

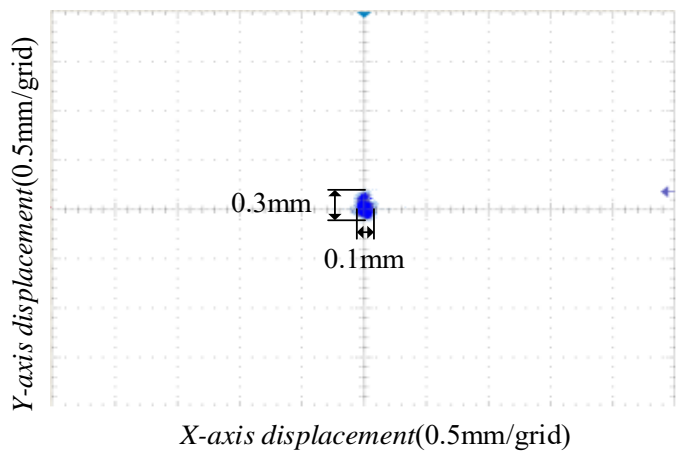

(b) Eccentric displacement

Fig. 10 Displacement waveform of bearingless and brushless DC motor

Figure 11 (a) and Figure 11 (b) are the radial displacement response curve and rotor trajectory diagram of the magnetic bearing. Since there is only a rotating shaft on one side of the magnetic bearing, it is less affected by gravity. Therefore, the displacement of the $\mathrm{x}$-axis and the y-axis are only $0.1 \mathrm{~mm}$, and the rotor track can be approximately seen as a circle.

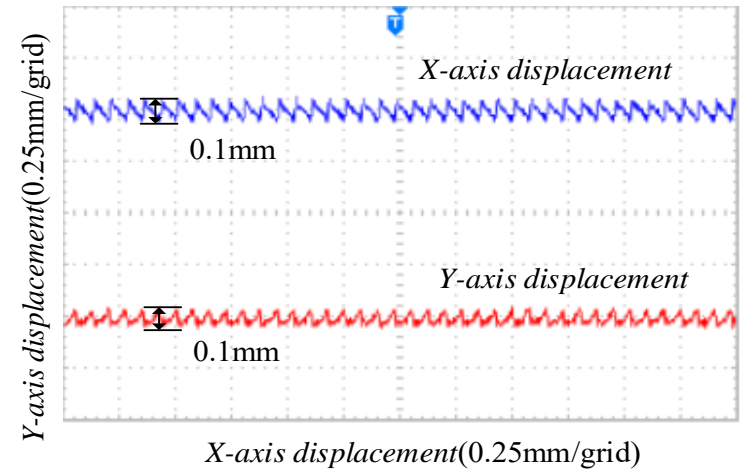

(a) Displacement in $\mathrm{x}$ and $\mathrm{y}$ directions

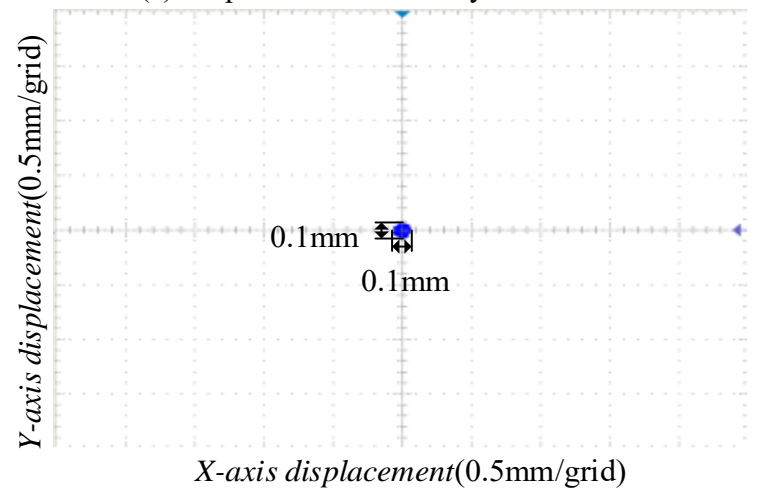

(b) Eccentric displacement

Fig. 11 Radial displacement waveform of magnetic bearing

Figure 12 is the floating waveform of the axial displacement of the magnetic bearing, showing the process of the magnetic bearing from starting to stabilizing. It can be seen from the figure that the axial position of the rotor takes $0.03 \mathrm{~s}$ from the initial state to the steady state. The response time is very short, the overshoot is about $0.4 \mathrm{~mm}$, and the overshoot is also very small. Meanwhile, the rotor is stable in the axial position. The axial displacement is about $0.4 \mathrm{~mm}$. It lasted for 0.54 seconds. The transient fluctuation of the rotor is $0.5 \mathrm{~mm}$, but it returns to 
the stable position quickly. The subsequent axial position of the rotor is relatively stable and the fluctuation is small, showing that the axial displacement control effect on the hybrid magnetic bearing is very good.

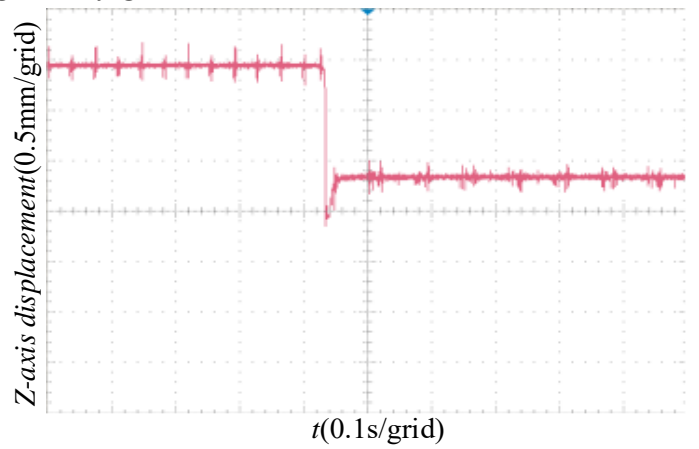

Fig. 12 Axial floating waveform of magnetic bearing

From the experimental results mentioned above, it can be seen that in the charging mode of the flywheel battery, the bearingless and brushless DC motor has a fast speed response, a small overshoot and a stable speed, while in the discharge mode, the DC voltage from the rectifier filter module is stable, and the frequency of the $\mathrm{AC}$ voltage generated by the inverter module is the same as the standard voltage frequency. Besides, the voltage model has good sinusoidal properties, which can be used as a stable power supply. Moreover, in the magnetic levitation experiment, both the bearingless and brushless DC motor and the magnetic bearing can be stably levitation, with a small fluctuation range, and can quickly reach a stable levitation state after starting in the axial direction, indicating that the magnetic levitation system proposed in the paper can be applied to flywheel batteries.

\section{CONCLUSION}

A five-degree-of-freedom magnetic levitation flywheel battery is proposed in the paper, which is composed of a two-degree-of-freedom bearingless and brushless DC motor and a three-degree-of-freedom hybrid magnetic bearing. Moreover, the principle of bearingless and brushless DC motor and magnetic bearing levitation force generation are analyzed, and a five-degree-of-freedom magnetic levitation flywheel battery control system is designed. Meanwhile, the control process is analyzed too. Besides, the matlab/simulink software is used for simulation research. Finally, a five-degree-of-freedom flywheel battery experimental platform is built. In addition, experiments are carried out on the charging mode (motor running state), power generation mode (generator running state) and magnetic levitation control system of the flywheel battery. The magnetic levitation control system includes the radial levitation research of the bearingless and brushless DC motor and the radial and axial levitation research of the magnetic bearing. Therefore, the research results show that the five-degree-of-freedom flywheel battery proposed in the paper has good working performance and stability, which lays a certain foundation for follow-up research.

\section{DISCUSSION}

In the charging mode of the flywheel battery, the bearingless and brushless DC motor has a fast speed response, a small overshoot and a stable speed, while in the discharge mode, the DC voltage from the rectifier filter module is stable, and the frequency of the $\mathrm{AC}$ voltage generated by the inverter module is the same as the standard voltage frequency. Besides, the voltage model has good sinusoidal properties, which can be used as a stable power supply. The magnetic levitation system proposed in the paper can be applied to flywheel batteries. the five-degree-of-freedom flywheel battery proposed in the paper has good working performance and stability, which lays a certain foundation for follow-up research. Therefore, further research is needed in the following aspects: the structure and working principle of bearingless brushless DC motor are relatively novel. In order to obtain more ideal suspension performance, the stator and rotor structure and winding form need to be optimized according to different working environment and requirements. A general method for static and dynamic simulation of bearingless brushless DC motor is established. In order to improve the robustness and anti-interference ability of the motor, a new digital controller can be used to optimize the hardware and software of the control system. In the control of bearingless brushless DC motor, the detection of motor rotor position is an important part, so the sensorless technology of bearingless brushless DC motor needs to be further studied

\section{ACKNOWLEDGMENT}

Natural Science Research Project of Universities in Jiangsu Province (20KJB470032); Science and Technology Planning Project of Yangzhou City (YZ2018072).

\section{References}

[1] A. M. Youssef, "Operations of electric vehicle traction system", Mathematical Modelling of Engineering Problems, Vol. 5, No. 2, pp. 51-57, 2018.

[2] O. Savadogo, "Will the future of electric vehicles be powered by accumulators or hydrogen PEM fuel cells?", Journal of New Materials for Electrochemical Systems, Vol. 23, No. 4, pp. 221-224, 2020.

[3] S. Karrari, H. R. Baghaee, G. De Carne, M. Noe, J. Geisbuesch, "Adaptive inertia emulation control for high-speed flywheel energy storage systems", IET Generation, Transmission \& Distribution, vol. 14, no. 22, pp. 5047-5059, 2020.

[4] S. Bouradi, K. Negadi, R. Araria, F. Marignetti, "Z-source inverter for energy management and vector control for electric vehicle based PMSM", Journal Européen des Systèmes Automatisés, Vol. 53, No. 6, pp. 883-892, 2020.

[5] T. A. Nguyen, "Control the hydraulic stabilizer bar to improve the stability of the vehicle when steering", Mathematical Modelling of Engineering Problems, Vol. 8, No. 2, pp. 199-206, 2021. 
[6] L. Jing, Y. Yu, X. Xue, "A Research on the Control System of High-Speed Homopolar Motor with Solid Rotor Based on Flywheel Energy Storage", Complexity, 2020.

[7] B. Xiang, W. Wong, "Power compensation mechanism for AMB system in magnetically suspended flywheel energy storage system", Measurement, vol. 173, pp. 108646, 2021.

[8] Z. Jin, X. Sun, Z. Yang, S. Wang, L. Chen, K. Li, "A novel four degree-of-freedoms bearingless permanent magnet machine using modified cross feedback control scheme for flywheel energy storage systems", International Journal of Applied Electromagnetics and Mechanics, vol. 60, no. 3, pp. 379-392, 2019.

[9] X. Sun, Z. Jin, S. Wang, Z. Yang, K. Li, Y. Fan, L.Chen, "Performance improvement of torque and suspension force for a novel five-phase BFSPM machine for flywheel energy storage systems", IEEE Transactions on Applied Superconductivity, vol. 29, no. 2, pp. 1-5, 2019.

[10]Z. Zhu, J. Zhu, X. Guo, Y. Jiang, Y. Sun, "Numerical Modeling of Suspension Force for Bearingless Flywheel Machine Based on Differential Evolution Extreme Learning Machine", Energies, vol. 34, no. 3, pp. 4470, 2019.

[11]Z. Q. Liu, K. Wang, F. Li, "Design and Analysis of Permanent Magnet Homopolar Machine for Flywheel Energy Storage System", IEEE Transactions on Magnetics, vol. 55, no. 7, pp. 1-6, 2019.

[12] Y. Yuan, Y. Sun, Q. Xiang, Y. Ren, Q. Liu, "The study of switched reluctance motor for 4-DOF bearingless motor", Journal of Electrical Engineering \& Technology, vol. 14, no. 1, pp. 179-189, 2019.

[13] S. Gorantla, R. Katuri, "A comparative study of ANN and pi controllers combined with MFB implemented to hybrid energy storage system for smooth switching between battery and ultracapacitor", Journal Europeen des Systemes Automatises, Vol. 52, No. 1, pp. 79-86, 2019.

[14] R. Katuril, S. Gorantla, "Performance analysis of hybrid controller for automatic switching between energy sources of hybrid energy storage system", European Journal of Electrical Engineering, Vol. 20, No. 5-6, pp. 617-630, 2018.

[15] K. Hamitouche, S. Chekkal, H. Amimeur, D. Aouzellag, "A new control strategy of dual stator induction generator with power regulation", Journal Européen des Systèmes Automatisés, Vol. 53, No. 4, pp. 469-478, 2020.

[16] T. A. Boghdady, S. N. Alajmi, W. M. K. Darwish, M. A. Mostafa Hassan, A. Monem Seif, "A Proposed Strategy to
Solve the Intermittency Problem in Renewable Energy Systems using a Hybrid Energy Storage System", WSEAS Transactions on Power Systems, Vol. 16, pp. 41-51, 2021.

[17] A. Bharathi Sankar, R. Seyezhai, "Super Capacitor/Battery based Hybrid Powered Electric Bicycle", WSEAS Transactions on Power Systems, Vol. 14, pp. 156-162, 2019.

Runxian Yang was born in Weinan City, Shanxi Province in 1979. She received Bachelor of Engineering Degree in electrical automation in 2002 and master degree in control engineering in 2007. Since 2016, she has been an Assistant Professor with the intelligent manufacturing department, Yangzhou Polytechnic Institute. She is the author of three books, her research interests include control theory and applied research, robotics, etc. She is a member of the expert for Jiangsu vocational college competition. Email: yangrxypi@163.com

Tao Tao was born in Yangzhou City, Jiangsu Province in 1988. $\mathrm{He}$ received Bachelor of Engineering Degree in electrical automation in 2010 and master degree in electrical automation in 2013. Since 2016, He has been a lecturer with the intelligent manufacturing department, Yangzhou Polytechnic Institute. He is the author of two books, his research interests include control theory and applied research, motor, etc. Email: taotao_ypi@163.com

\section{Author Contributions:}

Runxian Yang carried out the simulation and the optimization. Tao Tao was responsible for the experiment.

\section{Creative Commons Attribution License 4.0 (Attribution 4.0 International, CC BY 4.0)}

This article is published under the terms of the Creative Commons Attribution License 4.0 https://creativecommons.org/licenses/by/4.0/deed.en US 